\title{
Ischemic preconditioning improves maximal performance in humans
}

\author{
Patricia C. E. de Groot • Dick H. J. Thijssen • \\ Manuel Sanchez $\cdot$ Reinier Ellenkamp • \\ Maria T. E. Hopman
}

Accepted: 31 August 2009 / Published online: 18 September 2009

(C) The Author(s) 2009. This article is published with open access at Springerlink.com

\begin{abstract}
Repeated episodes of ischemia followed by reperfusion, commonly referred to as ischemic preconditioning (IPC), represent an endogenous protective mechanism that delays cell injury. IPC also increases blood flow and improves endothelial function. We hypothesize that IPC will improve physical exercise performance and maximal oxygen consumption. The purpose of the study was to examine the effect of ischemic preconditioning in leg skeletal muscles on cycling exercise performance in healthy individuals. Fifteen healthy, well-trained subjects performed two incremental maximal exercise tests on a bicycle ergometer. Power output, oxygen consumption, ventilation, respiratory quotient, and heart rate were measured continuously. Blood pressure and blood lactate were measured before and after the test. One exercise test was performed after the application of ischemic preconditioning, using a protocol of three series of 5-min ischemia at both legs with resting periods of $5 \mathrm{~min}$ in between. The other maximal cycling test served as a control. Tests were conducted in counterbalanced order, at least 1 week apart, at the same time of the day. The repeated ischemic periods significantly increased maximal oxygen consumption from 56.8 to $58.4 \mathrm{ml} / \mathrm{min}$ per $\mathrm{kg}(P=0.003)$. Maximal power output
\end{abstract}

P. C. E. de Groot · D. H. J. Thijssen · M. Sanchez · R. Ellenkamp ·

M. T. E. Hopman ( $\square)$

Department of Physiology,

Radboud University Nijmegen Medical Centre,

P.O. Box 9101, 6500 HB Nijmegen, The Netherlands

e-mail: m.hopman@ fysiol.umcn.nl

D. H. J. Thijssen

Research Institute for Sport and Exercise Science, Liverpool John Moores University, Liverpool, UK e-mail: d.thijssen@fysiol.umcn.nl increased significantly from 366 to $372 \mathrm{~W}(P=0.05)$. Ischemic preconditioning had no effect on ventilation, respiratory quotient, maximal heart rate, blood pressure or on blood lactate. Repeated short-term leg ischemia prior to an incremental bicycle exercise test improves maximal oxygen consumption by $3 \%$ and power output by $1.6 \%$. This protocol, which is suggested to mimic the effects of ischemic preconditioning, may have important implications for exercise performance.

Keywords Ischemia $\cdot$ Reperfusion - Oxygen uptake · Performance $\cdot$ Workload

\section{Introduction}

It has been demonstrated that brief, repeated periods of ischemia followed by reperfusion, commonly referred as "ischemic preconditioning" (IPC), causes a delay of lethal cell injury in (cardiac) muscles as well as in organs (Eisen et al. 2004; Murry et al. 1986; Reimer et al. 1986). Although the underlying mechanism(s) are not uniformly understood, the beneficial effects of IPC for cardiac and skeletal muscle cells to prevent ischemic damage are generally accepted.

From the available evidence, adenosine and ATP-sensitive potassium $\left(\mathrm{K}_{\mathrm{ATP}}\right)$ channels are identified to play, at least partly, a role in the effects of IPC. Administration of an adenosine-blocker (Hopper et al. 2000; Schroeder et al. 1996) or $\mathrm{K}_{\mathrm{ATP}}$-antagonist (Gross and Auchampach 1992; Hopper et al. 2000; Pang et al. 1997) attenuates the protective effects of IPC, while the protective effects are enhanced when agonists are administrated. An important consequence of elevated adenosine levels and ATP-sensitive potassium $\left(\mathrm{K}_{\mathrm{ATP}}\right)$ channels is an enhanced vasodilation. Interestingly, adenosine levels and ATP-sensitive potassium 
$\left(\mathrm{K}_{\mathrm{ATP}}\right)$ channels are also involved in matching the delivery of oxygen and substrates to the increased metabolic demand of muscles during exercise.

In addition to the effects of IPC on the vasculature, studies have found that IPC improves muscle function (Lawson and Downey 1993) and metabolism (Pang et al. 1995). Based on the effects of IPC on vessels and muscles, IPC prior to an exercise bout is hypothesized to improve physical exercise performance and maximal oxygen consumption in healthy subjects. Therefore, the aim of the present study is to examine the effect of IPC in leg muscles on oxygen consumption and workload during a maximal cycling test in healthy subjects.

\section{Methods}

\section{Subjects}

Fifteen healthy individuals (twelve males and three females, age $27 \pm 6$ years) volunteered to participate in this study. All subjects were well-trained cyclists and were nonsmokers. Based on their medical history, subjects did not have any medical problems and were free of any medication. Subject characteristics are summarized in Table 1. Prior to participation, all subjects gave their written

Table 1 Baseline subject characteristics $(n=15)$

\begin{tabular}{lc}
\hline Baseline characteristics & Mean \pm SD \\
\hline Age (years) & $27.2 \pm 5.6$ \\
Weight (kg) & $73.2 \pm 10.1$ \\
Height (cm) & $181 \pm 9$ \\
Sport time (h/week) & $7.8 \pm 3.9$ \\
Systolic blood pressure (mmHg) & $128 \pm 14$ \\
Diastolic blood pressure (mmHg) & $79 \pm 13$ \\
\hline
\end{tabular}

Values are expressed as mean $\pm \mathrm{SD}$ informed consent. The ethics committee of the Radboud University Nijmegen Medical Centre approved the study.

Protocol and measurements

All subjects refrained from alcohol, caffeine, and intensive physical exercise for at least $24 \mathrm{~h}$ prior to testing. All tests were performed in laboratory conditions with constant temperature $\left(20^{\circ} \mathrm{C}\right)$ and humidity $(35 \%)$.

Each subject reported to the laboratory twice and performed an incremental maximal exercise test on a cycling ergometer (Lode, Excalibur, Groningen, the Netherlands) at both days. The experiments were performed at least 1 week apart and at the same time of the day. Subjects were not informed about the rationale of the study, to prevent a placebo effect of IPC. One test was performed in combination with IPC. In order to banish possible confounding training or familiarization effects, the application of IPC was assigned in counterbalanced order. Seven subjects started the first maximal test without IPC, while eight subjects started the first maximal test preceded by IPC.

The incremental maximal cycling test started at a power output of $50 \mathrm{~W}$ for $4 \mathrm{~min}$, followed by $4 \mathrm{~min}$ at $100 \mathrm{~W}$ and $4 \mathrm{~min}$ at $150 \mathrm{~W}$. After this, the power output increased by $20 \mathrm{~W} / \mathrm{min}$ until exhaustion (Fig. 1). Subjects were instructed to keep cadence between 60 and $80 \mathrm{rpm}$.

Starting $2 \mathrm{~min}$ prior to and throughout the maximal exercise test, oxygen consumption $\left(\mathrm{VO}_{2}\right.$, in $\mathrm{ml} \mathrm{O}_{2} / \mathrm{kg}$ per min), ventilation ( $\mathrm{Ve}$, in $1 / \mathrm{min}$ ), respiratory quotient (RQ) (Oxycon IV, Jaeger, Germany), and heart rate (HR, in bpm) (Cardiotest EK 41, Depex, the Netherlands) were measured and recorded continuously. Manually, brachial artery blood pressure was measured before and immediately after each maximal exercise test. Blood lactate (mmol/l) was measured using Accutrend ${ }^{\circledR}$ Lactate (Roche Diagnostics GmbH, type 3012522, Mannheim, Germany) before and 2 min after finishing the maximal exercise test.
Fig. 1 Protocol of the study. $I P C$ ischemic preconditioning, $\mathrm{VO}_{2}$ max test incremental bicycle exercise test with measurement of maximal oxygen consumption, $L L$ left leg, $R L$ right leg. Gray square boxes represent 5-min arterial occlusion, alternated by 5 min without arterial occlusion (white boxes). During the maximal exercise test the gray boxes represent power output (W)

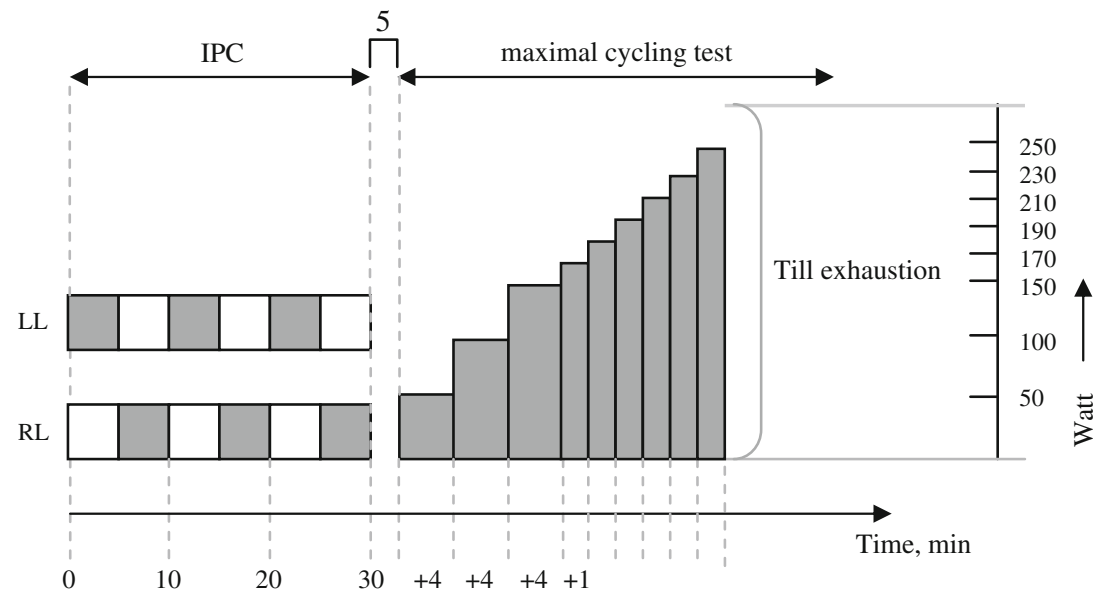




\section{Ischemic preconditioning}

Ischemic preconditioning (IPC) was performed in supine position using bilateral arterial occlusion. The occlusion cuffs were positioned proximally around the thigh and inflated to $220 \mathrm{mmHg}$ for $5 \mathrm{~min}$. This procedure allows a complete blockade of the arterial inflow in the lower limbs throughout these $5 \mathrm{~min}$ (Kooijman et al. 2008). This ischemic procedure was repeated three times, each separated by 5 min of reperfusion (Bushell et al. 2002). In animal studies, this IPC protocol was found to be optimal to protect rat muscles from ischemia-induced damage (Bushell et al. 2002). Five minutes after the IPC, the maximal exercise test started (Fig. 1).

\section{Data analysis}

Oxygen consumption, ventilation, and respiratory quotient were averaged over intervals of $30 \mathrm{~s}$. Resting values were averaged over a 2 -min period. The maximal values were represented as the mean of the last minute in which exercise was performed. In addition, oxygen consumption, ventilation, and respiratory quotient were analyzed during the 4-min steady state submaximal levels at 50, 100, and $150 \mathrm{~W}$ using the mean of the last $2 \mathrm{~min}$ in these periods.

\section{Statistics}

Data is presented as mean $\pm \mathrm{SD}$, unless stated otherwise. Shapiro-Wilk and Kolmogorov-Smirnov tests indicated a normal (Gaussian) distribution of data. Therefore, a twotailed paired Student's $t$ test was used to assess differences in oxygen consumption, power output, ventilation, respiratory quotient, maximal heart rate, blood pressure, and lactate concentration between the baseline and the IPC-maximal exercise test. Differences were considered to be statistically significant at $P \leq 0.05$.

\section{Results}

Baseline

Baseline characteristics were similar between both testing days (Table 1).

\section{Maximal performance}

Maximal oxygen consumption was significantly higher with IPC $58.4 \mathrm{ml} / \mathrm{min}$ per $\mathrm{kg}$ than without $56.8 \mathrm{ml} / \mathrm{min}$ per $\mathrm{kg}$ ( $t$ test: $P=0.003$; Fig. 2). Maximal power output reached higher values with IPC $372 \mathrm{~W}$ compared to without $366 \mathrm{~W}(P=0.05)$. Ventilation, respiratory quotient, maximal

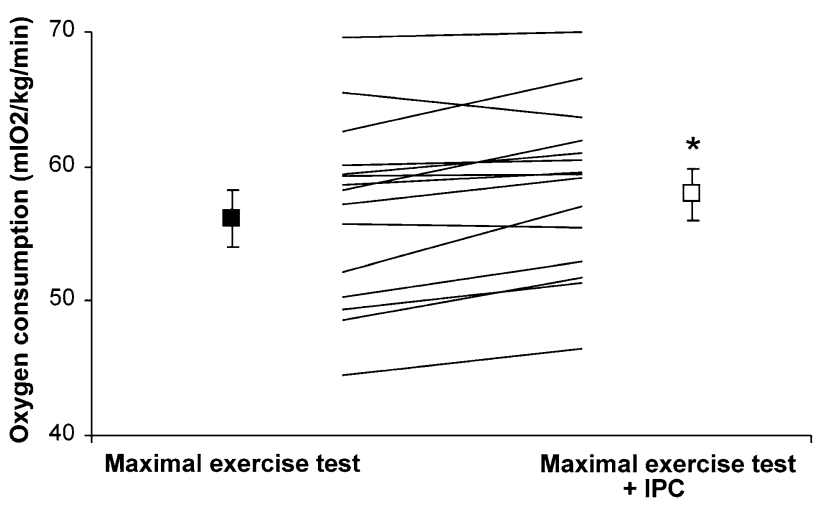

Fig. 2 Individual and mean maximal oxygen consumption $\left(\mathrm{VO}_{2} \mathrm{max}\right.$ in $\mathrm{ml} / \mathrm{min}$ per $\mathrm{kg}$ ) during the maximal exercise test without (black square) and with ischemic preconditioning (IPC, open square). $N=15$. Error bars represent SE. $* P<0.003$

heart rate, post-exercise blood pressure, and blood lactate concentrations were not different between both maximal cycling tests (with and without IPC) (Table 2).

\section{Submaximal performance}

At the submaximal levels of 50,100, and $150 \mathrm{~W}$, we confirmed the presence of a steady state, indicated by no further increase in oxygen consumption $\left(\leq 150 \mathrm{ml} \mathrm{O}_{2} / \mathrm{kg}\right.$ per min) during the last 2 min of each stage. Oxygen consumption, heart rate, ventilation, and respiratory quotient were not different between the IPC and non-IPC steady state levels of the cycling test (Table 2).

Table 2 Maximal oxygen consumption $\left(\mathrm{VO}_{2} \mathrm{max}\right)$, maximal power output, ventilation, respiratory quotient, maximal heart rate (HRmax), and blood pressure before the test started (BPrest) and immediately after finishing exercise (BPmax) presented as systolic/diastolic blood pressure (syst/diast), blood lactate, and oxygen consumption $\left(\mathrm{VO}_{2}\right)$ at 50,100 , and $150 \mathrm{~W}$ for the test without ischemic preconditioning (control) and the test preceded by ischemic preconditioning (IPC) in healthy young participants $(n=15)$

\begin{tabular}{llll}
\hline & Control & IPC & $P$ value \\
\hline$V \mathrm{O}_{2}$ max (ml/min per kg) & $56.8(6.8)$ & $58.4(6.2)$ & 0.003 \\
Maximal power output $(\mathrm{W})$ & $366(62)$ & $372(59)$ & 0.05 \\
Ventilation (1/min) & $143.4(29.7)$ & $148.9(22.6)$ & $\mathrm{NS}$ \\
Respiratory Quotient & $1.20(0.1)$ & $1.20(0.1)$ & $\mathrm{NS}$ \\
HRmax (bpm) & $183(9)$ & $183(7)$ & $\mathrm{NS}$ \\
BPrest syst/diast $(\mathrm{mmHg})$ & $130 / 83$ & $129 / 83$ & $\mathrm{NS}$ \\
BPmax syst/diast $(\mathrm{mmHg})$ & $177 / 66$ & $173 / 68$ & $\mathrm{NS}$ \\
Lactate $(\mathrm{mmol} / \mathrm{l})$ & $12.3(3.6)$ & $13.3(3.5)$ & $\mathrm{NS}$ \\
$V \mathrm{O}_{2}$ at $50 \mathrm{~W}(\mathrm{ml} / \mathrm{min}$ per kg) & $15.4(1.6)$ & $15.6(1.4)$ & $\mathrm{NS}$ \\
$V \mathrm{O}_{2}$ at $100 \mathrm{~W}(\mathrm{ml} / \mathrm{min}$ per kg) & $21.8(2.0)$ & $21.9(2.2)$ & $\mathrm{NS}$ \\
$V \mathrm{O}_{2}$ at $150 \mathrm{~W}(\mathrm{ml} / \mathrm{min}$ per kg) & $29.1(3.0)$ & $29.2(3.2)$ & $\mathrm{NS}$ \\
\hline
\end{tabular}

Values are expressed as mean (SD) 


\section{Discussion}

The major finding of the present study is that ischemic preconditioning of the legs in healthy subjects significantly increased maximal oxygen consumption by $3 \%$ and power output by $1.6 \%$ during maximal cycling performance. At submaximal exercise levels, IPC has no effect on any of the physiological variables. Although the underlying mechanism for this IPC-induced improvement in exercise performance needs to be elucidated, it may have profound consequences for exercise performance in athletes.

Unique in this study is the application of IPC to examine its effects on performance of the maximal cycling test in humans. The non-invasive nature and easy applicability of IPC are the important advantages. The descriptive nature of our study-design limits identification of the underlying mechanisms of the beneficial effects of the IPC on cycling performance. Since the effects of repeated short-term ischemia on muscle performance have never been examined before, the primary aim of the present study was to assess this effect and not to elucidate the underlying mechanisms.

The 3\% increase of maximal oxygen consumption after ischemic preconditioning in our trained subjects is comparable with the improvement in maximal oxygen consumption after $\sim 1$ month altitude training. Previous studies in well-trained (Levine and Stray-Gundersen 1997) or elite runners (Stray-Gundersen et al. 2001) demonstrated an increase in maximal oxygen consumption by 5 and $3 \%$, respectively, when a 4-week 'living high-training low' protocol was performed. In the present study we showed that a $\sim 20$-min session of IPC prior to an exercise test has similar improvements in maximal oxygen consumption compared with a well-established method for elite athletes to improve their performance. The $3 \%$ increase in oxygen consumption was in consonance with a significant and meaningful increase in maximal power output during the exercise test. Such improvement in maximal performance level is highly relevant in sports competition, since we know that during competitive events the difference between silver and gold can be minimal. As such, our results may have major implications for exercise performances at competitive levels.

This is the first human study that provides evidence that IPC beneficially alters performance level in humans. Given the explorative character of our study, we can only speculate about the possible mechanisms underlying the immediate improvement in cycling performance. Delivery of nutrients and oxygen to the peripheral tissues by blood is a potential limiting factor during exercise. Interestingly, previous studies suggested a positive impact of IPC on the vasculature, which may underlie the effects of IPC on exercise performance. The vasodilation response after exposure of rat muscles to IPC can be blocked using ATP-sensitive potassium channels $\left(\mathrm{K}_{\mathrm{ATP}}\right)$ blockers (Weselcouch et al.
1993), which suggests that activation of $K_{\text {ATP }}$ channels contributes to the effect of IPC on the vasculature. Interestingly, activation of $\mathrm{K}_{\mathrm{ATP}}$ channels also initiates functional sympatholysis in humans during exercise (Keller et al. 2004), an important integrative response during exercise to optimally meet the increased metabolic requirements through redistributing blood from inactive to active regions. In addition, another mechanism that relates to IPC-induced changes in the vasculature is adenosine, which is a potent vasodilator that contributes to the vasodilation response during exercise (Joyner and Proctor 1999). Therefore, adenosine may help to optimize the blood supply during exercise. Findings from studies that have blocked adenosine during IPC, support the idea that the protective effects of adenosine during IPC are mediated via adenosine receptor subtype $\mathrm{A}_{1}$ and $\mathrm{A}_{2 \mathrm{~B}}$ activation, expressed on cardiomyocytes and vascular endothelial cells (Rubio et al. 1999; Todd et al. 1996).

Although the changes in adenosine and $\mathrm{K}_{\mathrm{ATP}}$ channels may enhance maximal exercise-induced blood flow, this does not necessarily improve oxygen consumption, as $\mathrm{O}_{2}$ extraction can be decreased due to a less efficient flow distribution (Calbet et al. 2006). Interestingly, a previous study found a significant increase in muscle oxygenation during exhaustive exercise in rats treated with IPC compared to exercise in rats without IPC (Saito et al. 2004). They indicated that these differences cannot be explained by morphological differences, but rather relate to acute functional changes. Although studies should further examine these mechanisms, IPC-induced vascular adaptations may contribute to the higher oxygen uptake and elevated exercise performance found in our study.

In addition to IPC-induced changes in the vasculature, the improved performance level after IPC may also relate to adaptations in muscles, or more specifically in the mitochondria. To date, only two studies examined the effect of IPC on muscular performance in animals. One study found an improved force and contractility, as well as decreased fatigue in rat skeletal muscles after IPC (Lawson and Downey 1993). In addition, Pang et al. showed that IPC might protect pig skeletal muscles by promoting ATP-sparing during the subsequent ischemic event. It was speculated that ATP-sparing may have occurred through a tightening of excitation-contraction coupling, a reduction in futile ion pumping, and/or through a relatively lower reliance on anaerobic energy production without compromising force generation (Pang et al. 1995). If ATP-sparing occurred in our study, one may expect to find a more efficient muscle, leading to a larger work per oxygen consumed. However, power output at submaximal level was similar between both exercise bouts, while the increase in power output was comparable to the change in oxygen consumption at maximal cycling. 
Moreover, a recent study found that IPC is able to improve nitric oxide (NO) availability in young healthy adults (Kimura et al. 2007). In addition to potential vasodilator effects, it may also favorably impact upon the ability to consume oxygen during exercise, as NO has been shown to attenuate mitochondrial oxygen consumption through maintenance of an $\mathrm{O}_{2}$ extraction reserve (Cooper and Brown 2008; Prime et al. 2009).

Limitations Because the subjects were not blinded for the IPC intervention, one may argue that this might have influenced our results. However, subjects were blinded for the power output level and the time of performance during the test. In addition, participants were naïve and were not informed about the potential effect of IPC on exercise performance. Moreover, heart rate, respiratory quotient, and lactate levels were similar between both tests. These parameters indicate that during both exercise bouts, subjects performed a maximal performance that was not different between both days. Therefore, our study design had no impact on the major outcomes of our study. Another limitation relates to the fact that subjects started their exercise bout within 5 min after completing the IPC protocol. As a result, we examined the immediate impact of IPC and cannot extend our observations to a longer time-window between IPC and the start of exercise. As such, little is known about the optimal IPC protocol and timing to improve exercise performance.

In conclusion, an ischemic preconditioning protocol of three series of 5-min arterial occlusion of the legs in healthy subjects increases maximal oxygen consumption by $3 \%$ and power output by $1.6 \%$ during an incremental bicycle exercise test. We strongly support future studies to examine the potential impact of (different procedures of) IPC for exercise performance at competitive levels.

Acknowledgements We sincerely thank Jos Evers and Bregina Kersten for their assistance during the tests.

Conflict of interest statement None of the authors have any conflict of interest.

Open Access This article is distributed under the terms of the Creative Commons Attribution Noncommercial License which permits any noncommercial use, distribution, and reproduction in any medium, provided the original author(s) and source are credited.

\section{References}

Bushell AJ, Klenerman L, Taylor S, Davies H, Grierson I, Helliwell TR, Jackson MJ (2002) Ischaemic preconditioning of skeletal muscle. 1. Protection against the structural changes induced by ischaemia/reperfusion injury. J Bone Joint Surg Br 84:1184-1188

Calbet JA, Lundby C, Sander M, Robach P, Saltin B, Boushel R (2006) Effects of ATP-induced leg vasodilation on $\mathrm{VO}_{2}$ peak and leg $\mathrm{O}_{2}$ extraction during maximal exercise in humans. Am J Physiol Regul Integr Comp Physiol 291:R447-R453

Cooper CE, Brown GC (2008) The inhibition of mitochondrial cytochrome oxidase by the gases carbon monoxide, nitric oxide, hydrogen cyanide and hydrogen sulfide: chemical mechanism and physiological significance. J Bioenerg Biomembr 40:533-539

Eisen A, Fisman EZ, Rubenfire M, Freimark D, McKechnie R, Tenenbaum A, Motro M, Adler Y (2004) Ischemic preconditioning: nearly two decades of research. A comprehensive review. Atherosclerosis 172:201-210

Gross GJ, Auchampach JA (1992) Blockade of ATP-sensitive potassium channels prevents myocardial preconditioning in dogs. Circ Res 70:223-233

Hopper RA, Forrest CR, Xu H, Zhong A, He W, Rutka J, Neligan P, Pang CY (2000) Role and mechanism of PKC in ischemic preconditioning of pig skeletal muscle against infarction. Am J Physiol Regul Integr Comp Physiol 279:R666-R676

Joyner MJ, Proctor DN (1999) Muscle blood flow during exercise: the limits of reductionism. Med Sci Sports Exerc 31:1036-1040

Keller DM, Ogoh S, Greene S, Olivencia-Yurvati A, Raven PB (2004) Inhibition of KATP channel activity augments baroreflexmediated vasoconstriction in exercising human skeletal muscle. J Physiol 561:273-282

Kimura M, Ueda K, Goto C, Jitsuiki D, Nishioka K, Umemura T, Noma K, Yoshizumi M, Chayama K, Higashi Y (2007) Repetition of ischemic preconditioning augments endothelium-dependent vasodilation in humans: role of endothelium-derived nitric oxide and endothelial progenitor cells. Arterioscler Thromb Vasc Biol 27:1403-1410

Kooijman M, Thijssen DH, de Groot PC, Bleeker MW, van Kuppevelt HJ, Green DJ, Rongen GA, Smits P, Hopman MT (2008) Flowmediated dilatation in the superficial femoral artery is nitric oxide mediated in humans. J Physiol 586:1137-1145

Lawson CS, Downey JM (1993) Preconditioning: state of the art myocardial protection. Cardiovasc Res 27:542-550

Levine BD, Stray-Gundersen J (1997) Living high-training low: effect of moderate-altitude acclimatization with low-altitude training on performance. J Appl Physiol 83:102-112

Murry CE, Jennings RB, Reimer KA (1986) Preconditioning with ischemia: a delay of lethal cell injury in ischemic myocardium. Circulation 74:1124-1136

Pang CY, Yang RZ, Zhong A, Xu N, Boyd B, Forrest CR (1995) Acute ischaemic preconditioning protects against skeletal muscle infarction in the pig. Cardiovasc Res 29:782-788

Pang CY, Neligan P, Xu H, He W, Zhong A, Hopper R, Forrest CR (1997) Role of ATP-sensitive $\mathrm{K}+$ channels in ischemic preconditioning of skeletal muscle against infarction. Am J Physiol 273:H44-H51

Prime TA, Blaikie FH, Evans C, Nadtochiy SM, James AM, Dahm CC, Vitturi DA, Patel RP, Hiley CR, Abakumova I, Requejo R, Chouchani ET, Hurd TR, Garvey JF, Taylor CT, Brookes PS, Smith RA, Murphy MP (2009) A mitochondria-targeted S-nitrosothiol modulates respiration, nitrosates thiols, and protects against ischemia-reperfusion injury. Proc Natl Acad Sci USA 106(26): 10764-10769

Reimer KA, Murry CE, Yamasawa I, Hill ML, Jennings RB (1986) Four brief periods of myocardial ischemia cause no cumulative ATP loss or necrosis. Am J Physiol 251:H1306-H1315

Rubio R, Ceballos G, Balcells E (1999) Intravascular adenosine: the endothelial mediators of its negative dromotropic effects. Eur J Pharmacol 370:27-37

Saito T, Komiyama T, Aramoto H, Miyata T, Shigematsu H (2004) Ischemic preconditioning improves oxygenation of exercising muscle in vivo. J Surg Res 120:111-118

Schroeder CA Jr, Lee HT, Shah PM, Babu SC, Thompson CI, Belloni FL (1996) Preconditioning with ischemia or adenosine protects 
skeletal muscle from ischemic tissue reperfusion injury. J Surg Res 63:29-34

Stray-Gundersen J, Chapman RF, Levine BD (2001) Living high-training low altitude training improves sea level performance in male and female elite runners. J Appl Physiol 91:1113-1120

Todd J, Zhao ZQ, Williams MW, Sato H, Van Wylen DG, VintenJohansen J (1996) Intravascular adenosine at reperfusion reduces infarct size and neutrophil adherence. Ann Thorac Surg 62:13641372

Weselcouch EO, Sargent C, Wilde MW, Smith MA (1993) ATPsensitive potassium channels and skeletal muscle function in vitro. J Pharmacol Exp Ther 267:410-416 